\title{
AVALIAÇÃO DA INFLUÊNCIA DOS PRINCIPAIS ELEMENTOS FORMADORES DE ESCÓRIA NA MICROESTRUTURA DE PELOTAS DE MINÉRIO DE FERRO COM DIFERENTES BASICIDADES BINÁRIAS*
}

\author{
Ana Maria Guilherme Bailon ${ }^{1}$ \\ Heidy de Oliveira Simões ${ }^{1}$ \\ Raquel Ramos Almeida da Silva1 \\ Vinícius Perin Passigatti2 \\ Mauricio Marcos Otaviano ${ }^{3}$ \\ Thiago Marchezi Doellinger ${ }^{4}$
}

\section{Resumo}

A coesão entre os grãos de ferro em pelotas queimadas é afetada por mecanismos difusionais dependentes de tempo e temperatura de sinterização e do tipo de elementos presentes na escória. Óxidos presentes nos insumos e no minério exercem influência significativa no processo de difusão das partículas de ferro e na formação de escória, composta principalmente por $\mathrm{CaO}, \mathrm{SiO}_{2}, \mathrm{Al}_{2} \mathrm{O}_{3}$ e $\mathrm{MgO}$. $\mathrm{O}$ estudo da influência da escória na microestrutura de pelotas de minério de ferro permite um maior entendimento das principais características relacionadas às fases formadas, que afetarão diretamente sua resistência física e comportamento metalúrgico. Neste trabalho abordamos a influência da variação nos teores de $\mathrm{CaO}$ e $\mathrm{SiO}_{2}$ na estrutura das pelotas com o objetivo de verificar a interferência desses compostos na diminuição da energia livre superficial e crescimento de grão bem como na distribuição de porosidade e formação de fases como hematita, sílicatos, ferritos e, eventualmente, a magnetita. Para tal avaliação, pelotas com diferentes teores de escória passaram por caracterização química, análises em Microscópio Óptico e análises em Microscópio Eletrônico de Varredura.

Palavras-chave: Pelotas; Escória; Microestrutura.

\section{EVALUATION OF THE INFLUENCE OF THE KEY ELEMENTS IN SLAG FORMERS MICROSTRUCTURES IRON ORE PELLETS WITH DIFFERENT BASICITIES BINÁRIAS}

\section{Abstract}

Cohesion between the grains of iron in fired pellets is affected by diffusional mechanisms dependent on time and temperature of sintering and the type of elements present in the slag. Oxides present in the ore inputs and exert significant influence on the diffusion process of particles of iron and slag formation, composed mainly of $\mathrm{CaO}, \mathrm{SiO}_{2}, \mathrm{Al}_{2} \mathrm{O}_{3}$ and $\mathrm{MgO}$. The influence of slag on the microstructure of iron ore pellets allows a greater understanding of the main features related to phase formation, which will directly affect your stamina and metallurgical behavior. In this paper we discuss the influence of variation in $\mathrm{CaO}$ and $\mathrm{SiO}_{2}$ in the structure of the pellets in order to evaluate the influence of these compounds in reducing the surface free energy and grain growth as well as the distribution of porosity and formation of phases such as hematite, silicates, ferritos and possibly magnetite. For such an assessment, pellets containing different amounts of slag underwent chemical characterization, analysis on Optical Microscope and analysis in Scanning Electron Microscope.

Keywords: Pellets; Slag; Microstructure.

1 Graduanda em Engenharia Metalúrgica, Técnico de Processo, Gerencia de Engenharia de Processo de Ubu - Samarco Mineração, Anchieta-ES, Brasil.

2 Engenheiro Metalúrgico, Chefe de Equipe, Engenharia de Processo Ubu - Samarco Mineração, Anchieta-ES, Brasil.

3 Engenheiro Metalúrgico, Especialista Técnico de Mercado, Gerencia de Marketing - Samarco Mineração, Anchieta-ES - Brasil.

4 Engenheiro Metalúrgico, Chefe de Departamento, Engenharia de Processo Ubu - Samarco Mineração, Anchieta-ES, Brasil.

* Contribuição técnica ao 44 Seminário de Redução de Minério de Ferro e Matérias-primas, 15 Simpósio Brasileiro de Minério de Ferro e 2 Simpósio Brasileiro de Aglomeração de Minério de Ferro, 15 a 18 de setembro de 2014, Belo Horizonte, MG, Brasil. 


\section{INTRODUÇÃO}

Durante os processos de aquecimento e queima das pelotas segue-se uma sequência de alterações na estrutura destes aglomerados. Até $650^{\circ} \mathrm{C}$ ocorre perda de água absorvida ou capilar e da água combinada. Em seguida ocorre a decomposição térmica de fundentes e de impureza minerais bem como o ataque químico do $\mathrm{CaO}$ sobre a hematita, na faixa de $650^{\circ} \mathrm{C}$ a $1000^{\circ} \mathrm{C}$, seguido pela conversão gradual da hematita para magnetita, acima de $1350^{\circ} \mathrm{C}$. Na estapa final de queima, o processo de difusão é interrompido e ocorre a retirada forçada de calor das pelotas de $1350^{\circ} \mathrm{C}$ até a temperatura ambiente [1].

\subsection{Efeitos do CaO nas Pelotas}

O calcário adicionado à pelota visando neutralização da ganga ácida tem influência na temperatura de formação das fases líquidas e forte efeito sobre 0 comportamento físico e metalúrgico das pelotas. Durante o aquecimento, ocorre calcinação do calcário $\left(\mathrm{CaCO}_{3}\right)$, através da reação $\mathrm{CaCO}_{3} \rightarrow \mathrm{CaO}+\mathrm{CO}_{2}$, liberando dióxido de carbono $\left(\mathrm{CO}_{2}\right)$, que possibilita a geração de trincas devido à expansão volumétrica deste gás, Lingstan et al [2].

O monóxido de cálcio formado $(\mathrm{CaO})$ reage com o minério de ferro $\left(\mathrm{Fe}_{2} \mathrm{O}_{3}\right)$, formando compostos denominados ferritos de cálcio, de baixo ponto de fusão, os quais se mantêm líquidos nas temperaturas de queima, fluindo imediatamente pelos capilares existentes no interior das pelotas, devido à tensão superficial e/ou forças de capilaridade, para a superfície do $\mathrm{CaO}$, para as superfícies em torno das partículas de minério de ferro, para os vazios e para o interior das partículas de minério, através de poros abertos [3]. A cálcio diferrita $\left(\mathrm{CaO} .2 \mathrm{Fe}_{2} \mathrm{O}_{3}\right)$ durante o resfriamento decompõem-se em cálcio ferrita e hematita (hematita secundária). Tais reações afetam o coalescimento das partículas de minério de ferro favorecendo o processo de difusão, o crescimento dos grãos de ferro e a densificação da estrutura.

A Figura 1 mostra a influência da temperatura e do tempo de queima na resistência à compressão de pelotas para diferentes adições de calcário e temperaturas de queima.

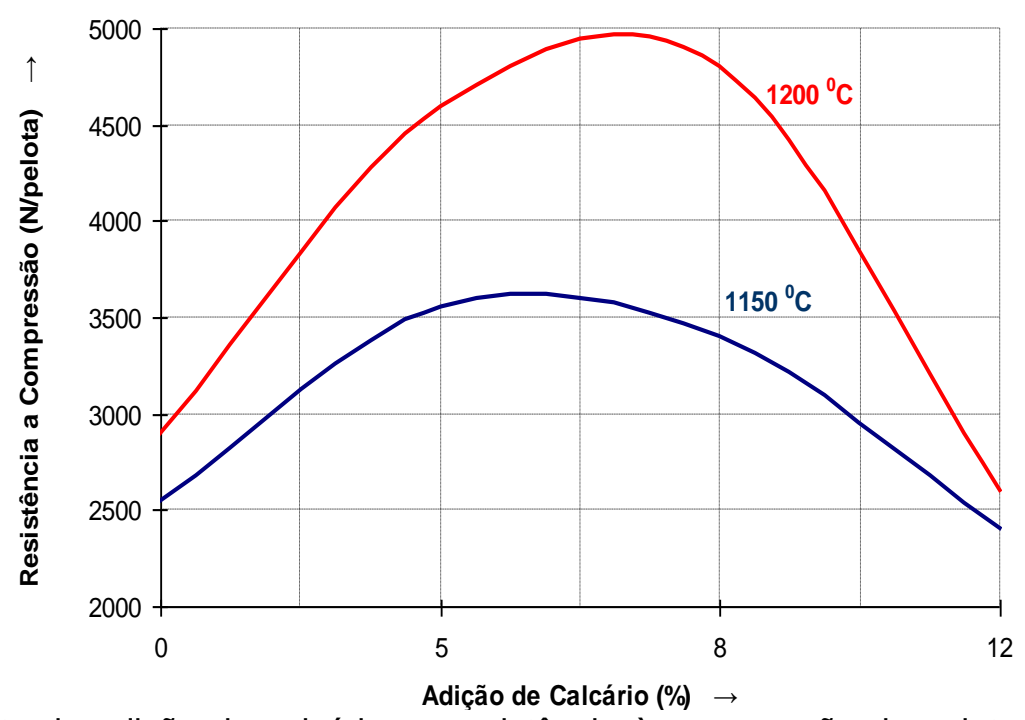

Figura 1 - Efeito da adição de calcário na resistência à compressão de pelotas de minério de ferro para diferentes temperaturas de queima.

* Contribuição técnica ao 44 Seminário de Redução de Minério de Ferro e Matérias-primas, $15^{\circ}$ Simpósio Brasileiro de Minério de Ferro e 2 Simpósio Brasileiro de Aglomeração de Minério de Ferro, 15 a 18 de setembro de 2014, Belo Horizonte, MG, Brasil. 


\subsection{Fontes de Energia no Coalescimento das Pelotas}

Em minérios hematíticos, são adicionadas fontes térmicas para que ocorram as reações de sinterização dos grãos, como carvão. Alguns exemplos de fontes de energia que podem contribuir para a sinterização são citados abaixo.

- A energia fornecida pelos gases do processo da queima das pelotas;

- A energia fornecida pelas reações exotérmicas da formação de ferritos e oxidação/reoxidação da magnetita;

- A energia fornecida pela queima de partículas de carvão dentro das pelotas.

Formação da ferrita: $O$ calor exotérmico causado pela formação deste constituinte pode levar a um superaquecimento e amolecimento do núcleo da pelota e a formação de uma estrutura vítrea por onde, durante o resfriamento, a reoxidação é impedida. A tendência de formação de magnetita das pelotas que contêm elevado valor de $\mathrm{CaO}$ pode ser reduzida através do abaixamento da temperatura de queima Meyer [4].

\subsection{Redução da Hematita pelo CO do Carvão}

Durante a combustão do carbono no interior da pelota ocorre um aumento de temperatura e uma redução na pressão parcial de oxigênio. Estes dois fatores favorecem a redução de hematita para magnetita. Como esta redução envolve uma mudança de estrutura cristalina, há uma geração de tensões que conduzem ao enfraquecimento das pelotas, conforme constatou Simões et al [5].

\subsection{Formação de sílicatos nas pelotas}

Partículas de $\mathrm{CaO}$ e $\mathrm{SiO}_{2}$ estão cercadas por óxidos de ferro nas pelotas, fazendo com que, durante a queima em forno industrial, ocorram reações entre grãos de ferro e os principais elementos da escória.

A formação de sílicatos de cálcio se dá através de uma reação secundária entre a fase líquida composta de $\mathrm{CaO}, \mathrm{Fe}_{2} \mathrm{O}_{3}$ e $\mathrm{SiO}_{2}$. A fase líquida flui através dos poros devido a forças de tensão interfacial e entra em contato com $\mathrm{SiO}_{2}$. Nesse contato a $\mathrm{SiO}_{2}$ é dissolvida e há a formação de sílicato de cálcio com precipitação de $\mathrm{Fe}_{2} \mathrm{O}_{3}$ (hematita secundária). A extensão dessa substituição, do $\mathrm{Fe}_{2} \mathrm{O}_{3}$ por $\mathrm{SiO}_{2}$, depende da quantidade de fase líquida presente e do tempo de reação, ou seja, quanto maior for a temperatura e tempo de queima maior será essa substituição [6].

\subsection{Sinterização e Crescimento dos Grãos de Hematita.}

A sinterização pode ser definida como um processo físico, ativado termicamente, de densificação e obtenção de resistência mecânica de uma estrutura composta por partículas em contato mútuo. A diminuição da energia livre superficial das partículas é a força motriz para que a sinterização ocorra, diminuindo a ocorrência de espaços vazios entre as partículas e aumentando a densidade.

Wynnyckyj e Fahidy [7], Monjardim [8] e German [9] descrevem a eficiência de sinterização em pelotas de minério de ferro, como sendo função: (i) da recristalização e crescimento dos grãos de hematita submetida a um determinado perfil de temperatura de queima; (ii) do tempo de permanência em cada temperatura e (iii) do crescimento do pescoço na interface entre os grãos, decorrente da mobilidade atômica do processo de difusão superficial e volumétrica.

* Contribuição técnica ao 44 Seminário de Redução de Minério de Ferro e Matérias-primas, $15^{\circ}$ Simpósio Brasileiro de Minério de Ferro e 2ํㅗํ Simpósio Brasileiro de Aglomeração de Minério de Ferro, 15 a 18 de setembro de 2014, Belo Horizonte, MG, Brasil. 
German [9] estudou dois tipos de sinterização, denominados sinterização por fase sólida e sinterização por fase líquida e concluiu que, embora ambas atuem no sentido de densificar a estrutura, os mecanismos que produzem tal densificação são totalmente distintos. Esses dois tipos básicos de sinterização são capazes de densificar total ou parcialmente a estrutura, sendo que com o primeiro tipo é possível se obter uma estrutura com porosidade controlada. Por sua vez, o fechamento total da porosidade é mais facilmente obtido através da sinterização por fase líquida.

Meyer [4], concluiu que há dois tipos de ligações térmicas que são decisivas para as propriedades das pelotas hematíticas:

1 - Mudança da estrutura cristalina durante a queima, por transformação ou crescimento dos cristais;

2 - Reação dos constituintes da escória formada que estão presentes como ganga nos minérios ou concentrados, ou adicionados antes da formação das pelotas, tais como bentonita, quartzo ou aditivos básicos.

Os componentes básicos reagem com os componentes ácidos e, sob certas condições, também com o óxido de ferro. Visto que os minérios ou concentrados sempre têm certa quantidade de ganga e que aditivos também são usualmente utilizados na produção das pelotas, ambos os mecanismos de ligação ocorrem simultaneamente sob condições normais de operação.

Batterham [10] descreveu que em pelotas com adição de fundentes, fases líquidas aparecem durante o aquecimento e o aumento na densidade pode ocorrer muito mais rapidamente. O reagrupamento das partículas pode levar a uma grande redução na área superficial e retração.

\section{MATERIAIS E MÉTODOS}

Para estudo do feito da escória sobre a estrutura e consequentes propriedades das pelotas foram produzidas, em laboratório, pelotas do tipo Alto-forno a partir de um minério com teor normal de sílica e pelotas com o dobro de sílica encontrada no minério. Variou-se a basicidade em dois níveis $(0,50$ e 1,0$)$ para os dois tipos de minério, o que permitiu uma avaliação também da influência dos níveis de basicidade sobre as características das pelotas. Os parâmetros temperatura do forno e percentual de carbono utilizado foram os mesmos para a produção de todas as pelotas.

Tabela 1 - Dados do Experimento

$\begin{array}{|c|c|}\hline \multicolumn{2}{|c|}{\text { Dados do experimento }} \\ \hline \text { Tipo de Minério } & \text { Basicidade Binária } \\ \hline \text { Minério com teor } & 0,5 \\$\cline { 2 - 2 } \text {$\left.normal de sílica } & 1,0 \\ \hline \text { Minério com teor } \\ \text { dobrado de sílica }\end{array}\right)$

As pelotas foram embutidas em resina acrílica e polidas para posterior avaliação em microscopia óptica e microscopia Eletrônica de varredura.

Utilizou-se, para a aquisição de imagens, um microscópio óptico de luz refletida modelo Imager M.2m com platina motorizada e dotado de câmera, com auxílio do software de análise de imagens AxioVision 4.8. Foi utilizado também um

* Contribuição técnica ao 44 Seminário de Redução de Minério de Ferro e Matérias-primas, $15^{\circ}$ Simpósio Brasileiro de Minério de Ferro e 2ํㅗํ Simpósio Brasileiro de Aglomeração de Minério de Ferro, 15 a 18 de setembro de 2014, Belo Horizonte, MG, Brasil. 
microscópio eletrônico de varredura Jeol modelo JSM-6360, com espectrômetro por dispersão de raio-X (EDS) acoplado.

\section{RESULTADOS E DISCUSSÕES}

A tabela 2 mostra o impacto da variação do teor de sílica do minério e do índice de basicidade na resistência física e formaço de fases que compoõem a estrutura da pelota.

\begin{tabular}{|c|c|c|c|c|c|c|c|}
\hline \multicolumn{8}{|c|}{ Resultados } \\
\hline & \multirow{2}{*}{$\begin{array}{c}\text { Basicidade } \\
\text { Binária }\end{array}$} & \multirow{2}{*}{$\begin{array}{c}\text { Variação na Resistência } \\
\text { a Compressão com } \\
\text { Relação ao Padrão } \\
\text { Samarco } \\
\end{array}$} & \multicolumn{5}{|c|}{$\begin{array}{c}\text { Avaliaçao Microestrutural } \\
\text { Percentual de fases }\end{array}$} \\
\hline & & & Poros & Hematita & Magnetita & Silicatos & Ferritos \\
\hline \multirow{2}{*}{$\begin{array}{c}\text { Minério com teor } \\
\text { normal de sílica }\end{array}$} & 0,5 & $0 \%$ & 41,39 & 48,00 & 8,51 & 1,77 & 0,33 \\
\hline & 1,0 & $7 \%$ & 46,80 & 36,22 & 13,72 & 2,69 & 0,55 \\
\hline \multirow{2}{*}{$\begin{array}{l}\text { Minério com teor } \\
\text { dobrado de sílica }\end{array}$} & 0,5 & $-9 \%$ & 31,17 & 47,01 & 16,33 & 4,57 & 0,91 \\
\hline & 1,0 & $-25 \%$ & 37,09 & 27,87 & 26,72 & 7,19 & 1,11 \\
\hline
\end{tabular}

Para o minério com teor normal de sílica a elevação no índice de basicidade elevou a resistência física da pelota, isto porque, em teores controlados, a presença de maior quantidade de escória aumenta a resistência física do aglomerado.

As pelotas produzidas com o dobro do teor de sílica no minério, para os níveis de basicidade binária estudados, apresentaram queda na resistência física, principalmente quando a basicidade binária foi aumentada para 1,0 .

Diferenças significativas na estrutura das pelotas foram observadas quando se variou o teor de sílica do minério e a basicidade binária $(0,50$ e 1,0). A figura 3 mostra mosaicos das pelotas que passaram por avaliação macro e microestrutural. É possível observar variação de macroporosidade entre as amostras.
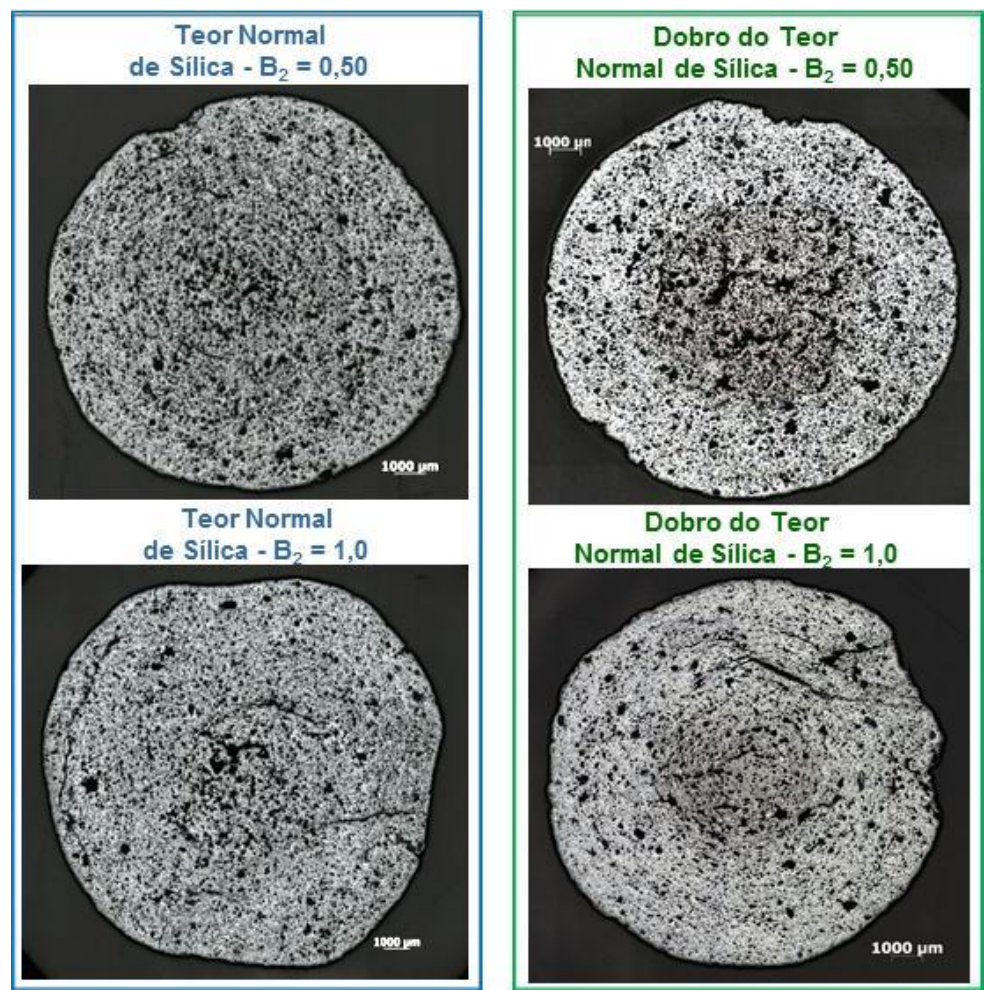

Figura 2. Mosaicos de pelotas selecionadas para avaliação macro e microestrutural.

* Contribuição técnica ao $44^{\circ}$ Seminário de Redução de Minério de Ferro e Matérias-primas, $15^{\circ}$ Simpósio Brasileiro de Minério de Ferro e 2ํㅗํ Simpósio Brasileiro de Aglomeração de Minério de Ferro, 15 a 18 de setembro de 2014, Belo Horizonte, MG, Brasil. 
A figura 4 mostra a microestrutura das pelotas em microscópio óptico com magnificaçao de 500x onde é possível observar maior porosidade nas pelotas produzidas com teor normal de sílica. Em contrapartida, na microestrutura das pelotas com teor de sílica aumentado, observam-se grãos de elevado tamanho, confirmando o favorecimento das reações de coalescimento dos grãos em presença de elevada quantidade de escória. A escória que estava liquida durante os estágios finais da sinterizaçao preencheu os poros e alterou 0 tamanho de grão. Todas as pelotas apresentaram magnetita em sua estrutura. Os teores de silicatos, ferritos e magnetita foram maiores em pelotas com teor mais elevado de sílica e com maior basicidade.
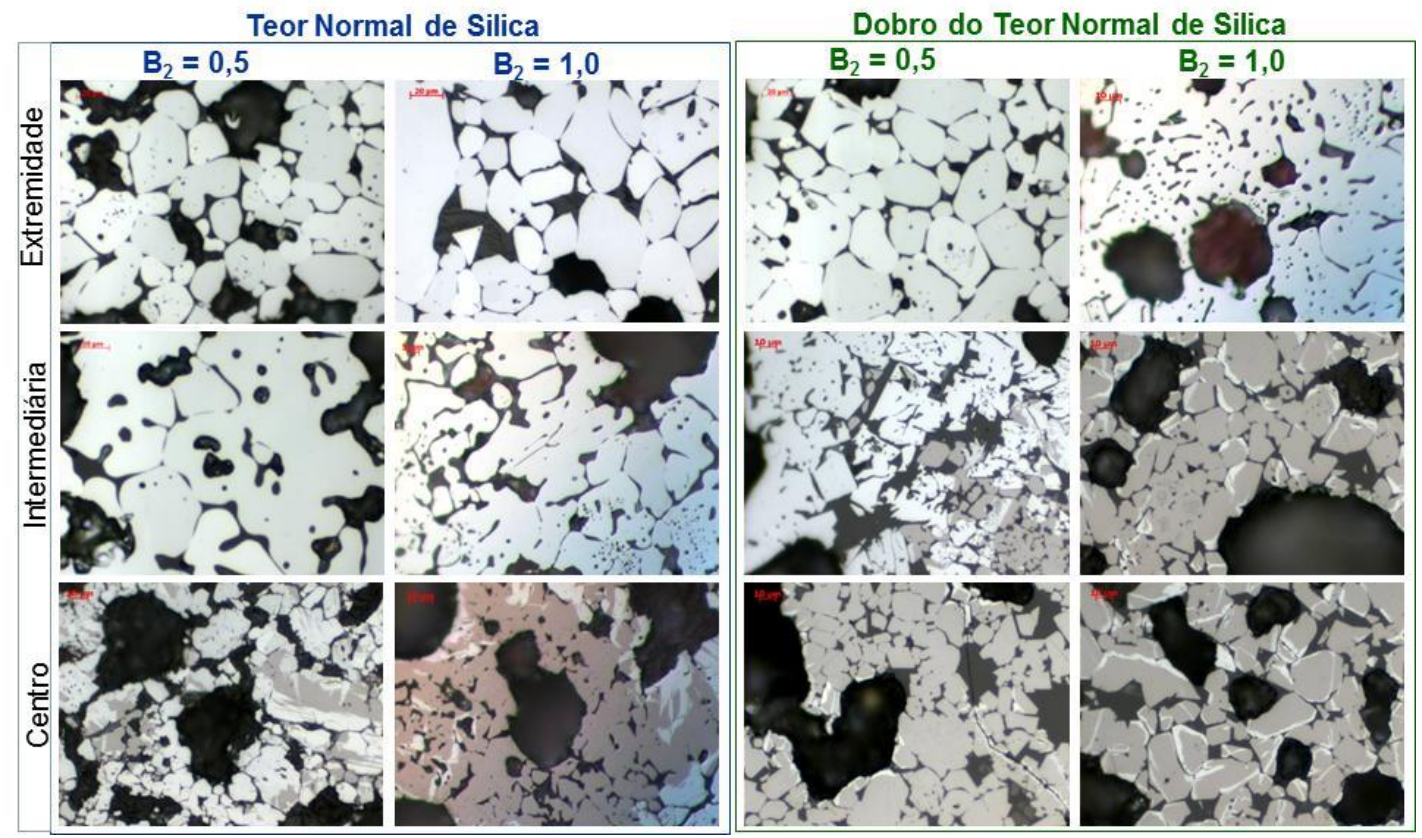

Figura 3. Microestruturas com magnificação de 500x. Observa-se a diferença na porosidade e formação de magnetita nas amostras.

Utilizou-se neste trabalho uma metodologia para quantificação do tamanho de grãos desenvolvida por Simões et al [5]. A figura 4 mostra gráficos dos resultados obtidos. Quanto à contagem de grãos, verificou-se uma menor quantidade de grãos para pelotas produzidas a partir de minério com teor de sílica aumentado. Isto se deve ao fato de existirem grãos maiores ocasionados pelas condições físico químicas propiciadas por maior disponibilidade de $\mathrm{CaO}$ nestas amostras.
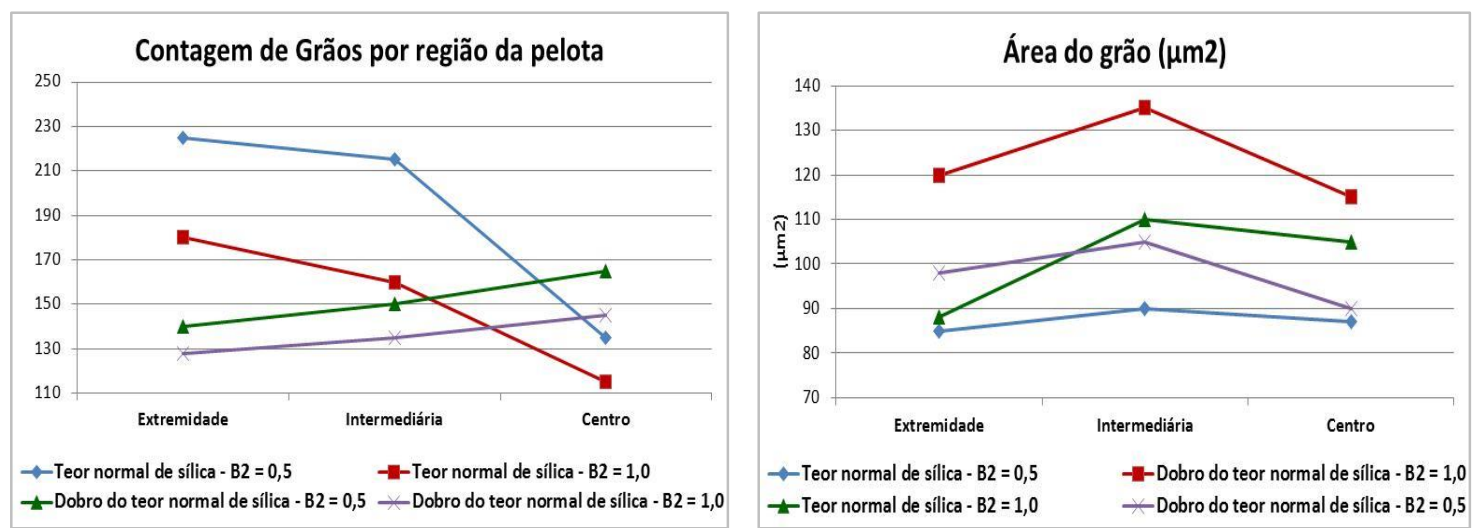

Figura 4. Gráficos mostrando a contagem de grãos e tamanho dos grãos microestruturais encontrados nas pelotas.

* Contribuição técnica ao 44ํㅗㄹ Seminário de Redução de Minério de Ferro e Matérias-primas,

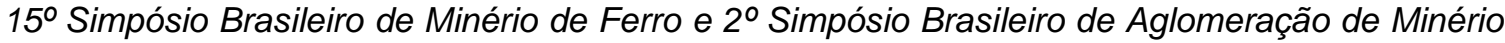
de Ferro, 15 a 18 de setembro de 2014, Belo Horizonte, MG, Brasil. 
O tamanho dos grãos nas pelotas com maior teor de escória tende a diminuir da extremidade para a o centro da pelota indicando que a sinterização foi mais eficiente na extremidade destas pelotas. Esta diferença indica que os gases aquecidos do forno tiveram dificuldades de chegar ao centro da pelota, devido a grande quantidade de silicatos que preenchem os poros durante o processo de sinterização.

Durante a sinterização, ocorrem ligações do tipo sólido-sólido entre partículas de ferro. A ausência da fase líquida (silicatos) nestas ligações resulta em menor crescimento de grão propiciando maior permeabilidade aos gases aquecidos do forno pela pelota. A figura 5 mostra este tipo de ligação em pelotas de baixo teor de escória.
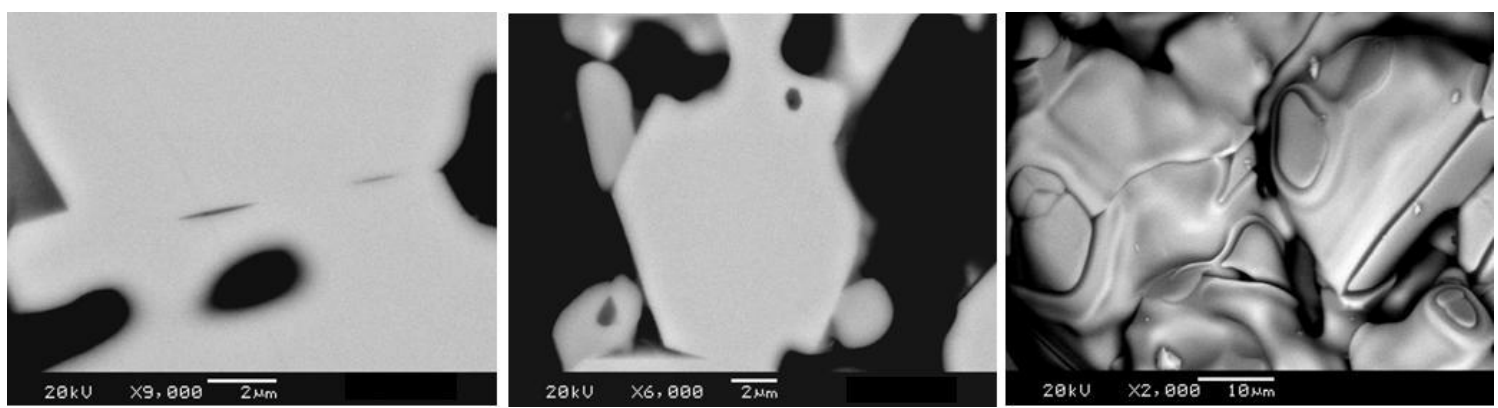

Figura 5. Ligações entre grãos de hematita, do tipo sólido-sólido, em pelotas de minério de ferro.

Nas pelotas deste experimento houve maior incidência de ligações do tipo sólido-líquido durante a sinterização. A interação entre a fase sólida (ferro) e a líquida (silicatos) provoca alteração no tamanho dos grãos de ferro envolvidos por elementos que auxiliam no processo de difusão como, por exemplo, o cálcio. A figura 6 mostra ligações do tipo sólido-líquido em pelotas de alta basicidade.
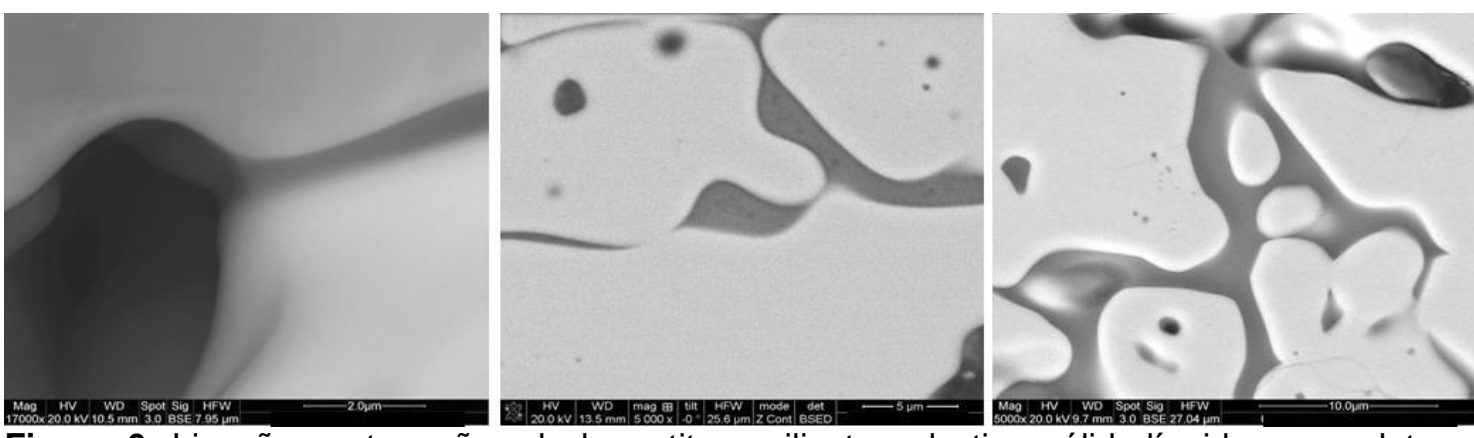

Figura 6. Ligações entre grãos de hematita e silicatos, do tipo sólido-líquido, em pelotas de minério de ferro.

A figura 7 mostra imagens de pelotas com teor normal de sílica obtidas em microscópio eletrônico de varredura com diferentes magnificações. É possível notar maior tamanho de grão e quantidade de escória entre os grãos da amostra com basicidade de 1,0 .

* Contribuição técnica ao 44 Seminário de Redução de Minério de Ferro e Matérias-primas, 15 Simpósio Brasileiro de Minério de Ferro e 2 Simpósio Brasileiro de Aglomeração de Minério de Ferro, 15 a 18 de setembro de 2014, Belo Horizonte, MG, Brasil. 

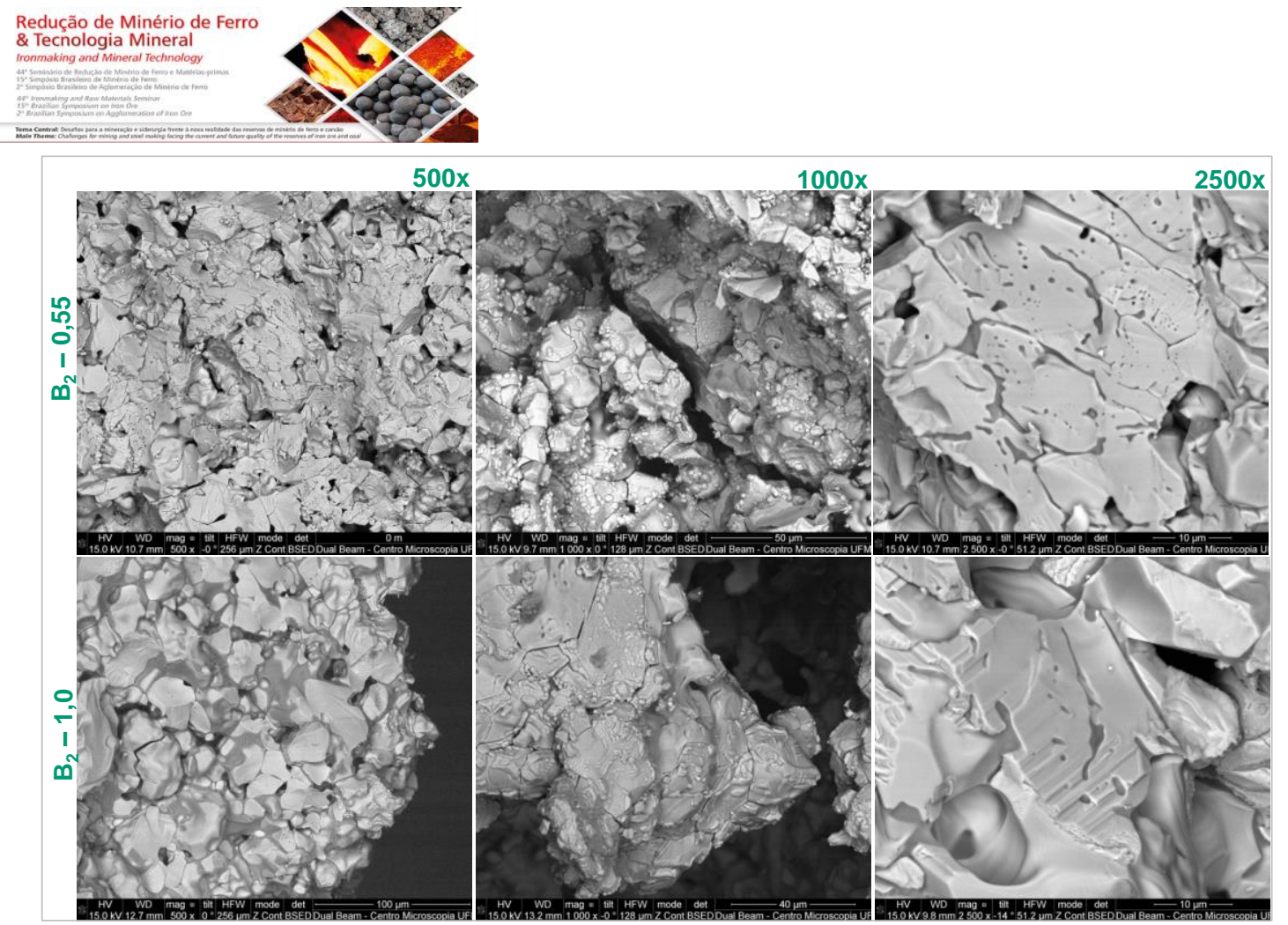

Figura 7. Imagens obtidas em microscópio eletrônico de varredura mostrando tamanho dos grãos das pelotas com teor de sílica normal e basicidade binária de 0,50 e 1,00.

Para as pelotas com o dobro do teor de sílica, evidenciou-se que a formação de altos níveis de escória impacta de forma diferente na microestrutura. Para uma mesma basicidade, quando amentado o percentual de sílica é demanda uma elevada quantidade de $\mathrm{CaO}$. Como consequência, eleva-se o teor de escória, afetando a difusão.

Há um elevado tamanho do grão nas regiões de extremidade e intermediária da pelota. Em contrapartida, os grãos da região central da pelota são menores, como pode ser observado na figura 8 , onde as regiões são comparadas na magnificação de 2500x.
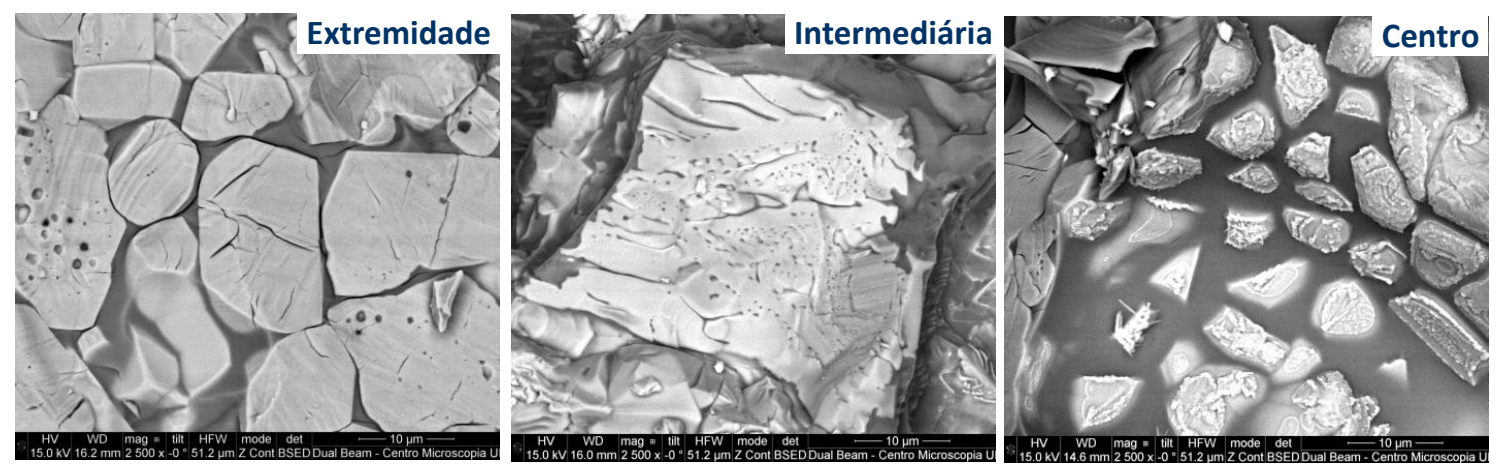

Figura 8. Imagens obtidas em microscópio eletrônico de varredura mostrando tamanho dos grãos das regiões de extremidade, intermediária e centro de pelotas com teor normal de sílica.

Além do elevado crescimento de grão, foram identificadas estruturas típicas de ocorrência do processo de recristalização no centro da pelota, caracterizadas pela morfologia dos grãos que aparecem surgindo de dentro dos silicatos.

A figura 9, na magnificação de 1000x em microscópio ótico mostra estrutura rica em magnetita com silicatos portadores de pequenos grãos de ferro diluídos indicando que o processo de recristalização está ocorrendo nesta pelota.

A Figura 8B, na magnificação de 5000x em microscópio eletrônico de varredura mostra a morfologia da magnetita formada na mesma região.

* Contribuição técnica ao 44 Seminário de Redução de Minério de Ferro e Matérias-primas, 15 Simpósio Brasileiro de Minério de Ferro e 2 Simpósio Brasileiro de Aglomeração de Minério de Ferro, 15 a 18 de setembro de 2014, Belo Horizonte, MG, Brasil. 

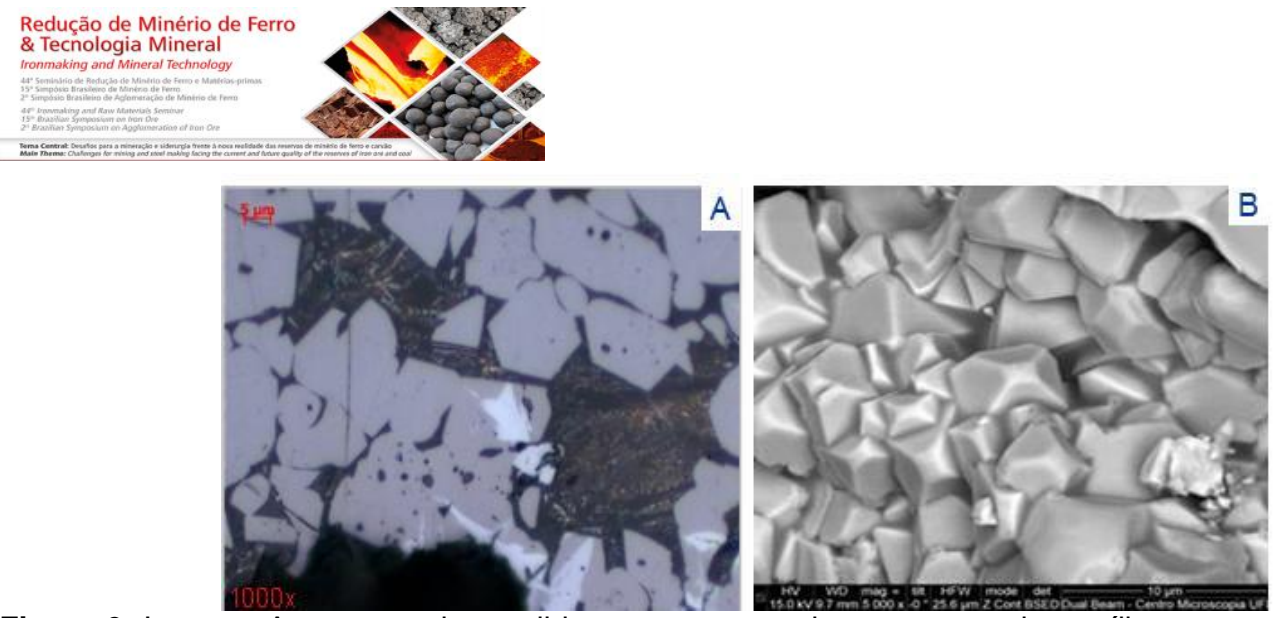

Figura 9. Imagem A mostra pelota polida com estrutura rica em magnetita e sílicatos portadores de grãos de ferro em processo de recristalização. Imagem B não polida mostra morfologia da magnetita encontrada.

A figura 10 A e B, obtida em microscópio eletrônico de varredura mostra cristais de ferro emergindo da escória fluida.

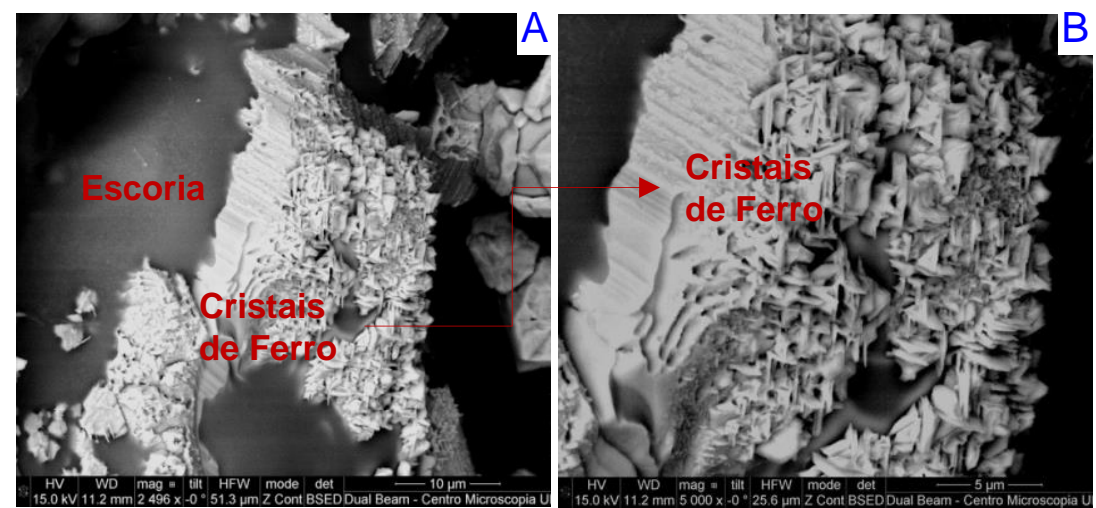

Figura 10. Estrutura de recristalização do ferro envolto por escória.

Seguindo uma sequência no processo de sinterização, depois da recristalização ocorre o crescimento de grão e consequente densificação da estrutura, o que ocorreu de forma diferente nas pelotas com teor de sílica aumentado.

No centro da pelota impermeabilizada pelo elevado tamanho de grãos e quantidade de silicatos que cobriram os poros, a energia para as reações foi obtida pela queima do carvão, não havendo oxigênio necessário para a oxidação da magnetita, nem temperatura adequada para o crescimento de grão, como ocorreu na extremidade das pelotas. A figura 11 mostra poros impermeabilizados pelo elevado teor de escória.

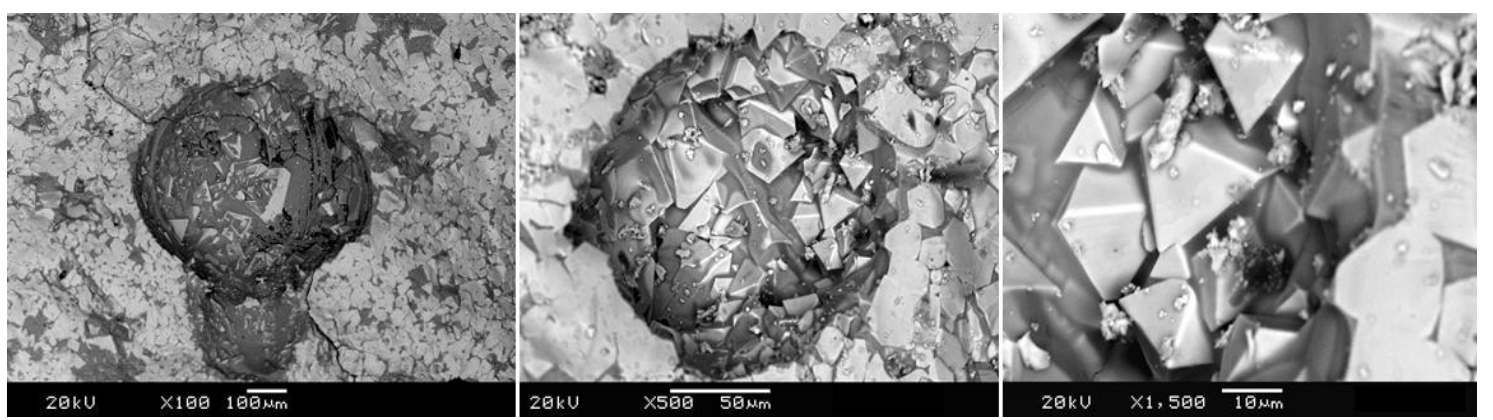

Figura 11. Poro de pelota impermeabilizada por elevada quantidade de escória e com magnetita em seu interior.

A falta de permeabilidade também impactou na manutenção da fase magnetita desde o centro da pelota até a região intermediária devido à dificil difusão e propagação de calor para o interior das pelotas.

* Contribuição técnica ao 44 Seminário de Redução de Minério de Ferro e Matérias-primas, $15^{\circ}$ Simpósio Brasileiro de Minério de Ferro e 2ํㅗํ Simpósio Brasileiro de Aglomeração de Minério de Ferro, 15 a 18 de setembro de 2014, Belo Horizonte, MG, Brasil. 
No centro da pelota mais rica em escória foram encontrados grãos pequenos envolvidos pela escória fluida em estrutura fechada. As figuras 12 A e B mostram microestrutura densificada onde não é possivel a passagem de gases aquecidos para o interior da pelota. As figuras $12 \mathrm{C}$ e $\mathrm{D}$ mostram grãos de magnetita e trincas na região avaliada.

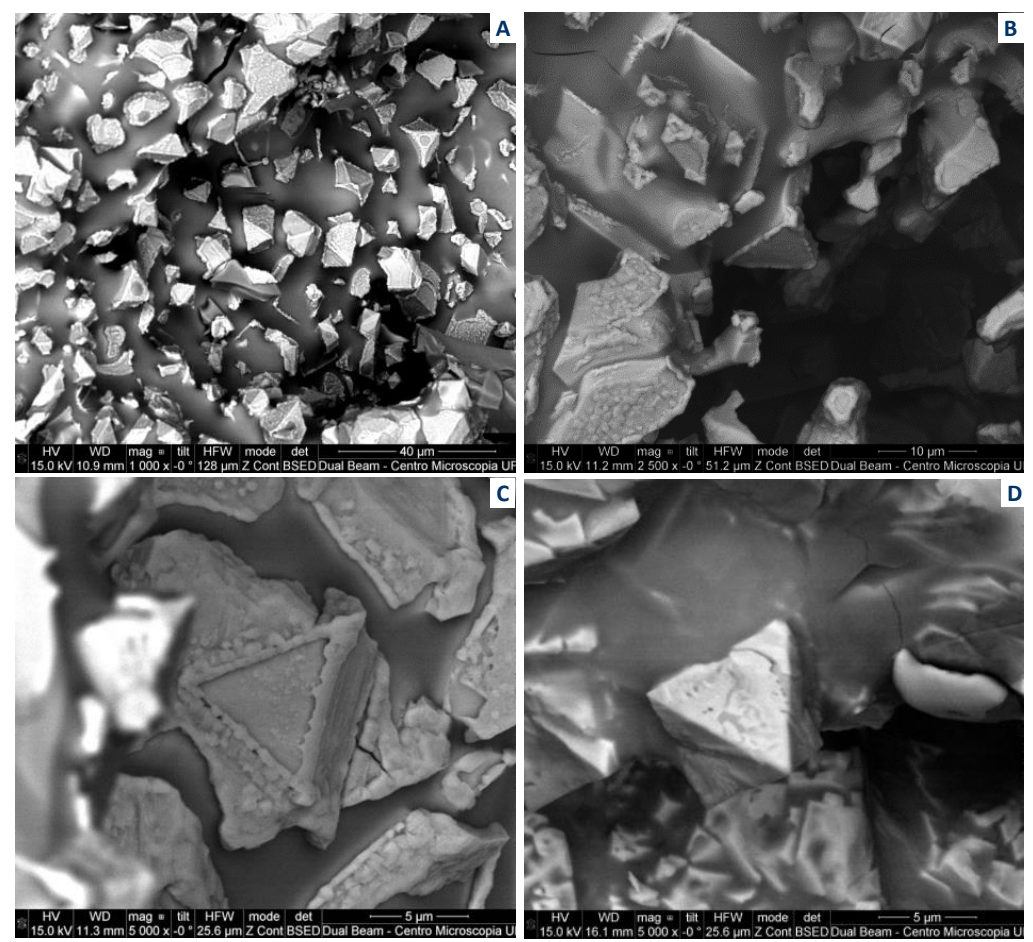

Figura 12. Imagens de diferentes magnificações mostrando a estrutura cúbica de face centrada CFC) da magnetita, caracterizada por octaedros, nos grãos envolvidos pela escória.

A microestrutura das pelotas indicou que havia excesso de energia na produção do aglomerado. Este fato foi evidenciado pelo tensionamento da estrutura e por trincas.

As figuras $13 \mathrm{~A}, \mathrm{~B}$ e $\mathrm{C}$ foram obtidas em microscópio ótico e mostram estrutura com magnetita e trincas. A figura $13 \mathrm{D}$, obtida em microscópio eletrônico de varredura, mostra estrutura rica em silicatos e muito tensionada apresentando trincas. Estes fatores levaram a perda de resistência física do material.
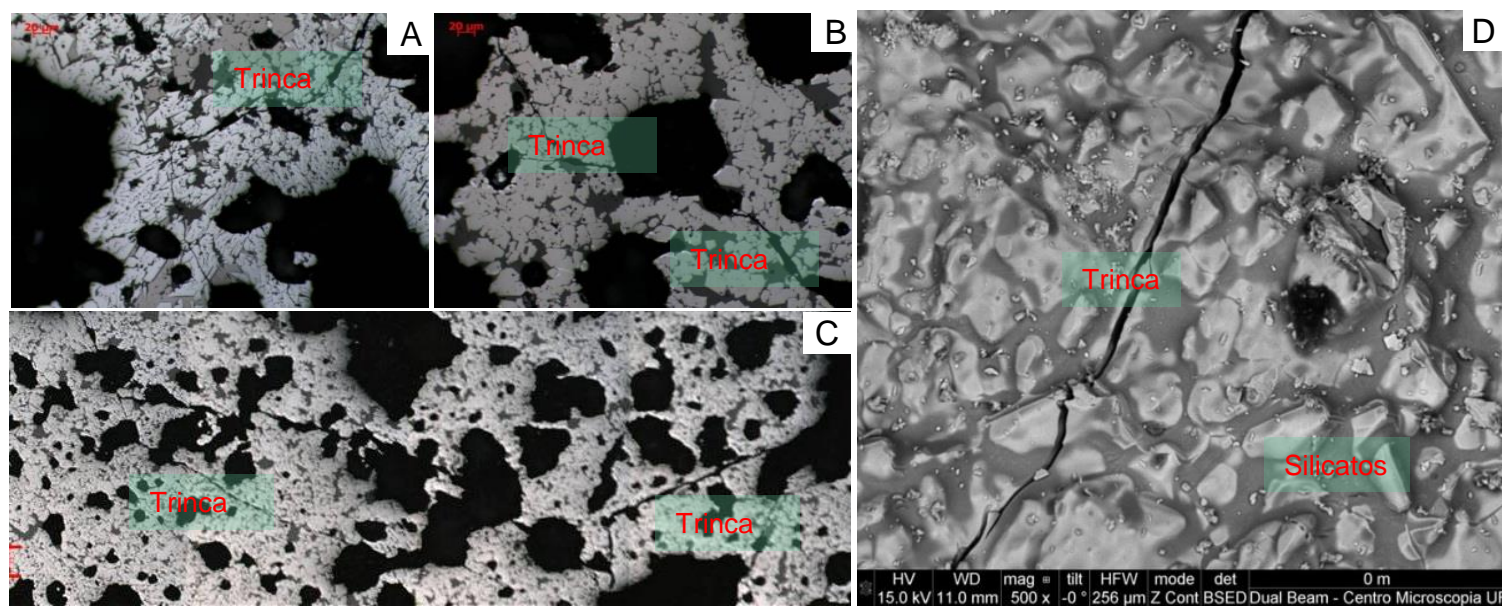

Figura 13. Microestruturas em microscópio ótico mostrando trincas e poros em estrutura magnetítica (A, $B$ e C) e imagem em Microscópio eletrônico de varredura mostrando estrutura fechada, rica em escória e com trincas (D).

* Contribuição técnica ao 44ํㅗㄴ Seminário de Redução de Minério de Ferro e Matérias-primas, 15 Simpósio Brasileiro de Minério de Ferro e 2ํ Simpósio Brasileiro de Aglomeração de Minério de Ferro, 15 a 18 de setembro de 2014, Belo Horizonte, MG, Brasil. 


\section{CONCLUSÕES}

A avaliação de pelotas com diferentes teores de escória e níveis de basicidade binária mostrou a forte influência destes parâmetros sobre a microestrutura e resistência física das pelotas.

Para teores normais de sílica foi observada uma melhora nas propriedades físicas das pelotas ao se elevar o nível de basicidade binária.

Para pelotas com teor de sílica aumentado o comportamento foi contrário quanto à qualidade física. A elevação da basicidade binária (de 0,5 para 1,0$)$ em pelotas Samarco tipo Alto-forno produzidas com minério de teor normal de sílica acarretou na elevação da resistência física. Ao elevar-se a basicidade (de 0,5 para 1,0) de pelotas produzidas com o dobro do teor de sílica no minério, obteve-se queda na resistência física.

A identificação de estruturas de recristalização, manutenção da magnetita no interior das pelotas e a impermeabilização do aglomerado com alto teor de escória, denota a falta de condições termodinâmicas ideais para densificação da estrutura da pelota. $O$ teor das principais fases constituintes da microestrutura das pelotas variou no experimento realizado, e refletiu as características físicas do aglomerado quanto à resistência a compressão. O tamanho dos grãos de hematita e a quantidade de poros, silicatos e ferritos teve a influência da variação de basicidade das pelotas.

\section{Agradecimentos}

Os autores agradecem a Samarco Mineração pelo suporte e incentivo.

\section{REFERÊNCIAS}

1 Wendling F. Reações Químicas No Processamento Térmico - Curso De Especialização Em Sistemas Mínero-Metalúrgicos - Ufop-Nupec-Fg - 2003.

2 Lingstan K, Yang L, Lu, W-K., The Role Of Magnesia In Iron Ore Pellets. Scandinavian Journal Of Metallurgy, 1983; 4: 166-176.

3 Costa RVP - Otimização Da Resistência Â Compressão Das Pelotas De Minério De Ferro Utilizadas Em Reatores De Redução Direta Pela Aplicação De Projeto Robusto - Dissertação De Mestrado, Redemat - Ouro Preto, 2008.

4 Meyer K. Pelletizing Of Iron Ores. Germany: Springer - Verlag Berlin Heidelberg New York, 1980 - 302 P.

5 Simões HO, Bailon AMG, Pereira BCE, Doellinger TM. Desenvolvimento de uma Metodologia para Determinação do Grau de Sinterização dos Grãos em Pelotas de Minério de Ferro através de Análise Automática ee Imagens. XIII Simpósio Brasileiro de Minério de Ferro, 14-18 de Outubro de 2012, Rio de Janeiro.

6 Silva FD. Redução do Delta de Resistência à Compressão entre Pelotas Produzidas e Embarcadas nas Usinas de Pelotização da Vale - Uma Análise de Causas - Pós-Graduação em Engenharia Minera, Universidade Federal de Ouro Preto - Ouro Preto, 2010.

7 Wynnyckyj JR, Fahidy TZ. Solid State Sintering In The Induration of Iron Ore Pellets, Metallurgical Transactions, 1974; 5: 991-999.

8 Monjardim MB. Estudo da Formação de Escória e sua Influência na Resistência Mecânica dos Aglomerados de Minério de Ferro depois de Queimados ao Ar. Dissertação de Mestrado PUC-RJ, Rio de Janeiro, Brasil, 1980.

9 German RM. Fundamentals of Sintering - Ceramics and Glasses Handbook; Volume 4, 1983, P. $260-269$.

10 Batterham RJ. Modeling the Development of Strength in Pellets - Metalurgical Transactions B, 1986;17b: 479-486.

* Contribuição técnica ao 44 Seminário de Redução de Minério de Ferro e Matérias-primas, $15^{\circ}$ Simpósio Brasileiro de Minério de Ferro e 2ํㅗํ Simpósio Brasileiro de Aglomeração de Minério de Ferro, 15 a 18 de setembro de 2014, Belo Horizonte, MG, Brasil. 